\section{An ancestor's influence}

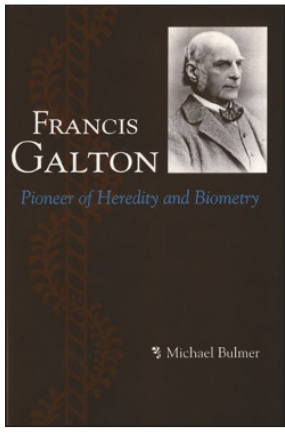

\section{Francis Galton: Pioneer of Heredity and Biometry}

By Michael Bulmer

The Johns Hopkins University Press, 2003

$376 \mathrm{pp}$. hardcover, $\$ 45$

ISBN 0-8018-7403-3

\section{Reviewed by Joe Felsenstein}

In the decades between Darwin's Origin of Species and the rediscovery of mendelian inheritance, there were a number of attempts to construct mathematical theories of heredity and evolution. All failed, owing to the lack of a theory of heredity. The most impressive of these attempts was Francis Galton's “Law of Ancestral Heredity”. Galton's theory was developed further by Karl Pearson, and their work was important in the development of modern statistics, giving us the term 'regression', modern notions of partial and multiple correlation, the $\chi^{2}$ statistic and much else. But their work on heredity was ultimately eclipsed by the development of modern quantitative genetics, which based itself securely on mendelian principles.

This book is not so much an account of Galton's life and works (others have recently published extensive and thoughtful biographies) as a monograph on how Galton's arguments worked, and how they do or do not fit into mendelian quantitative genetics. Bulmer is not an historian of science but is a contributor to contemporary quantitative genetics, particularly to the theory of variation of quantitative traits in natural populations.

The first chapter concisely summarizes Galton's life, giving ample credit to the two main published biographies of Galton and mentioning his African explorations and his wide range of scientific interests, from alpinism to fingerprints to meteorology. The next two chapters give a more extended consideration of Galton's collection of pedigrees of eminent Englishmen, his pioneering use of twins, and the conclusion he drew from these-that variation in ability was mostly genetic rather than environmental. Galton was not only the leading hereditarian of his age; he also coined the word 'eugenics' and was considered the founder of the eugenics movement. Bulmer does not shrink from where this led: he discusses the fate of eugenic movements in Britain, the US and Germany, including anti-immigration movements and Nazi eugenics.

Joe Felsenstein is in the Department Genome Sciences and the Department of Biology at the University of Washington, Seattle, Washington 98195-7360, USA.e-mail: joe@gs.washington.edu
With a sure hand, Bulmer leads us on from Galton's advocacy of eugenics to his attempts to grapple with the mechanism of heredity, on which he corresponded with his cousin Charles Darwin and did experiments on rabbits. Then it's on to evolutionary work on animal domestication, gregariousness, fertility of heiresses, extinction of surnames and an almost-relevant theory of the evolution of sex. Then we see Galton struggle mightily with the properties of the normal distribution of two variables.

As impressive as Galton's achievements were, the high point of the book for me is the chapters on the statistical theory of heredity and the Law of Ancestral Heredity. Particularly here, we benefit from Bulmer's expertise. Galton and Pearson formulated the Law in various ways at various times, but always as a regression equation predicting the phenotype of an individual from the phenotypes of its ancestors, going back many generations. Always it involved a series of coefficients, regressing phenotype on the mean of the two parents, the mean of the four grandparents, the mean of the eight great-grandparents and so on. Each was expressed as its departure from its own population mean.

Galton and Pearson regarded their Law as empirical and not assuming any particular mechanism of heredity. Yet Bulmer argues that Galton implicitly assumed an inheritance of hereditary particles, which could be either expressed or latent in each generation but were passed on. Although this comes close to being mendelian, Galton does not allow the particles to segregate out-his theory is both particulate and blending at the same time. From the continual dilution of particles Galton infers that the regression coefficients declined in a geometric progression as one went to more and more remote ancestors.

There have been claims that Galton's Law of Ancestral Heredity was consistent with mendelian inheritance, although it failed to allow for dominance. Bulmer convincingly rejects this view, pointing out that Galton's incomplete understanding of statistics led him to confuse the contributions of generations with their regression coefficients in the prediction equation. He derives the formulas for the latter. They do decline geometrically, but at rates that differ from character to character according to the heritability. For characters of low heritability, the decline is slow, as each generation is an imperfect predictor of the offspring, and phenotypes of more remote ancestors add more information. But for high heritabilities, once the midparent is known, information from more remote ancestors adds little to our predictive power. Galton and Pearson continued a futile search for a single regression equation.

Bulmer's carefully argued book is an essential resource for anyone trying to understand the abortive Victorian attempts to quantify heredity and construct a mathematical theory of evolution. Its examination of Galton's theories in the light of modern quantitative genetics has been criticized (by Eileen Magnello in Nature) as "present-minded," failing to understand Galton in his own terms. We have no difficulties analyzing R.A. Fisher's great 1918 paper in modern terms, or even Pearson's 1904 paper on mendelism. Why, then, should we not go back another 15 years to the Law of Ancestral Heredity? I found Bulmer's book illuminating, an intense experience well worth having. 